\title{
Oxovanadium(IV) Complexes with Triazole Based Schiff Base Ligands: Synthesis, Characterization and Antibacterial Study
}

\author{
Bharat Prasad Sharma ${ }^{1}$, Sarvesh Kumar Pandey², Bishnu Prasad Marasini ${ }^{3}$, \\ Sabita Shrestha ${ }^{1}$, Motee Lal Sharma*1 \\ ${ }^{1}$ Central Department of Chemistry, Tribhuvan University, Kirtipur, Kathmandu, Nepal \\ ${ }^{2}$ Department of Chemistry, DDU Gorakhpur University, Gorakhpur, U.P., PIN: 273 009, India \\ ${ }^{3}$ Nepal Health Research Council, Ministry of Health and Population, Kathmandu, Nepal \\ *Corresponding E-mail: mlsharma@cdctu.edu.np \\ (Received: March 3, 2020; Revised: November 1, 2020; \& Accepted: December 9, 2020)
}

\begin{abstract}
Schiff bases have been synthesized by the reaction of triazole containing primary amine with aromatic carbonyl compounds. The Schiff bases prepared, act as ligand when these are made in contact with oxovanadium $\left(\mathrm{VO}^{2+}\right)$ ion. Some new mononuclear oxovanadium(IV) complexes have been synthesized by the reaction of Schiff base ligands with vanadyl sulphate $\left(\mathrm{VOSO}_{4} \cdot \mathrm{xH}_{2} \mathrm{O}\right)$ and the complexes are analyzed by different spectroscopic methods; [fourier-transform infrared (FTIR), ultraviolet-visible (UV-Vis.), electron paramagnetic resonance (EPR)], X-ray diffraction (XRD) analysis, elemental analysis and conductivity measurement. The complexes have been well characterized based on analytical data. The electrolytic nature of the complexes was determined based on the molar conductance values. The powder XRD pattern has been used to determine crystal size and type. The synthesized Schiff base ligands and oxovanadium(IV) complexes were found to be stable in air and moisture at room temperature. On the basis of the physicochemical data, the tentative geometry of the complexes has been proposed. Antibacterial sensitivity of the ligand and its metal complexes have been assayed in vitro against bacterial pathogens viz. growth inhibitory activity of ligands and complexes against pathogens has also been determined.
\end{abstract}

Keywords: Schiff base, oxovanadium(IV) complexes, antibacterial activity, spectroscopy, triazole

\section{Introduction}

Schiff bases are versatile ligands and played an influencing role in the development of coordination chemistry and were involved at key points in the development of the relationship among organic synthesis, inorganic chemistry and biochemistry $[1,2]$. Schiff base derivatives in various processes promoted the researchers for designing the novel heterocyclic Schiff bases for the development of new environmental-friendly technology [3]. Nowadays, the bioinorganic chemists target the nitrogen-containing organic compounds as heterocyclic ligands and their metal complexes to study their pharmacology as the focus of research due to their wide range of biological activities such as antibacterial [4,5], antifungal [6], antitumor [7], antidiabetic [8], anticancer [9] and antiviral activities [10]. The chemistry of oxovanadium(IV) has received significant attention, as the $\mathrm{VO}^{2+}$ unit can coordinate a different type of donor atoms to form different types of complexes [11]. Nowadays, most of the research directed on coordination complexes of $\mathrm{VO}^{2+}$ because it is probably the most relevant species present in biological systems since a number of systematic model studies have carried out on the interaction of this oxo-cation with different biomolecules and other ligands of biological and pharmacological interest in order to contribute to a better understanding of its possible roles and functions in living organisms [12]. Keeping in view the medicinally important properties of Schiff bases [13] and the potential bioactivity of vanadium metal [14], researcher find it valuable to combine both the chemistry of these two moieties and evaluate their coordination behavior and bioactive nature [15] which results into the study of coordination behavior and biological activity of different acyclic 
and macrocyclic Schiff base ligands towards oxovanadium(IV) [16]. The present work aims the synthesis and characterization of oxovanadium(IV) derivatives with triazole based multidentate Schiff base ligands.

\section{Materials and Methods}

The solvents and chemicals used during the study were of reagent grade and used without any further purification. Benzoic acid, 2-chlorobenzoic acid, 2-hydroxy benzoic acid (salicylic acid), methanol, sulfuric acid, potassium hydroxide, sodium bicarbonate, carbon disulfide, benzil, etc. were available in our research laboratory of the Central Department of Chemistry, Tribhuvan University, Kirtipur. Hydrazine hydrate, vanadium sulfate, were purchased from Avantor performance materials India limited, Maharashtra, India. All the experimental procedures were carried out at room temperature in an ordinary condition. The physical properties of the synthesized triazoles, ligands and complexes were determined during the experiments. The solubility of all the samples was tested in ethanol, ether, tetrahydro furan (THF), dimethyl sulfoxide (DMSO), acetonitrile, etc. The melting points were determined carefully using Thiel's tube. The purity of synthesized compounds was checked with TLC.

\section{Synthesis of Schiff bases}

When an aromatic carboxylic acid (o-chloro and $o$-hydroxy benzoic acid), allowed to refluxed with methanol at $50^{\circ} \mathrm{C}$, results in the formation of ester. The hydrazide was formed when ester was allowed to refluxed with hydrazine hydrate in methanol after that the 1,3,4-triazole was formed by the reaction of hydrazide with $\mathrm{KOH}, \mathrm{CS}_{2}$ and hydrazine hydrate in methanol. When the methanolic solution of two triazoles synthesized from two different starting aromatic carboxylic acid (o-chloro and $o$-hydroxy

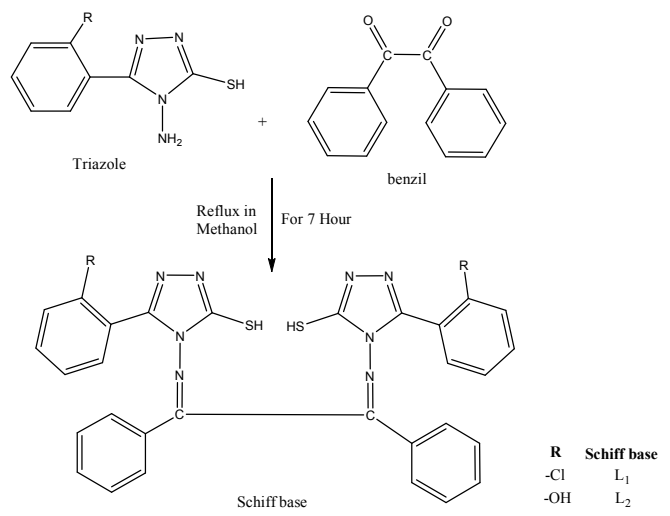

Figure 1: Synthetic route to Schiff bases benzoic acid) were allowed to be refluxed with the carbonyl compound, Benzil, it results in the formation of two different Schiff bases [5].

\section{Synthesis of oxovanadium(IV) complexes}

The methanolic solution of the vanadyl sulfate was

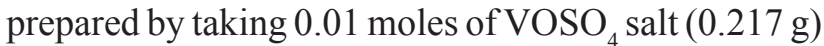
and was added to a methanolic solution of 0.1 moles of Schiff base. The reaction mixture was refluxed for 8 hours at $45^{\circ} \mathrm{C}$ which results into the formation of the complex $[2,17]$. Then, the mixture was allowed to cool at room temperature overnight and the compound was separated in the form of crystals from the clear solution of the mixture by filtration, washed with ether and dried.

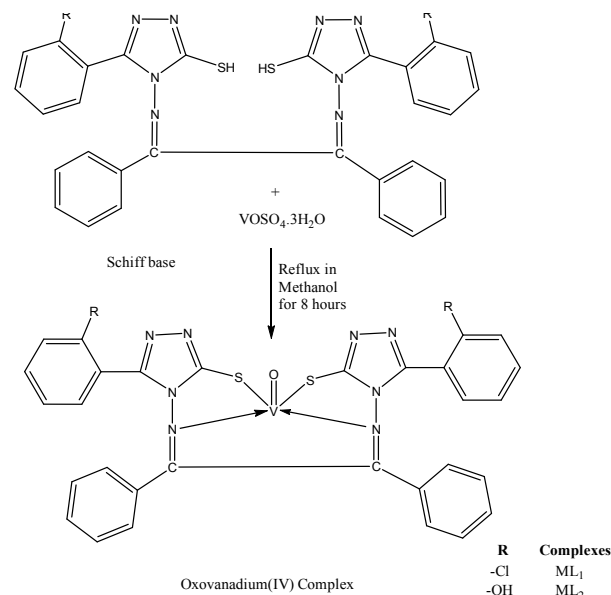

Figure 2 : Synthesis of oxovanadium(IV) complexes

Synthesized samples were analyzed using UV-Vis. electronic spectra on a double beam spectrophotometer of Labtronics Model LT-2802. The FTIR spectra of all the ligands and complexes prepared were analyzed by using Fourier Transform Infrared Spectrometer of model IR Tracer 100, Shimadzu, Japan. The oxovanadium(IV) complex, $\mathrm{ML}_{1}$, prepared was analyzed for the phase detection using an X-ray Diffractometer with monochromatic $\mathrm{Cu}-\mathrm{K} \alpha$ radiation ( $\mathrm{D}_{2}$ phase Diffractometer, Bruker, Germany). The sample was scanned at a $2 \theta$ angle of 2 to 80 degrees. The solution of the sample $\mathrm{ML}_{1}$ and $\mathrm{ML}_{2}$ were prepared in synthetic grade DMSO solution (manufactured in Mumbai, India) in $10^{-3} \mathrm{M}$ concentration for the molar conductance measurement by using DELUX CONDUCTIVITY METER of model-601 and serial no. of 17051032 made in India. The solid-state X-band EPR spectrum for oxovanadium(IV) complex has been recorded at room temperature at field set $3200 \mathrm{G}$ $(=0.32 \mathrm{~T})$, microwave power $5 \mathrm{~mW}$ and microwave frequency $9.1 \mathrm{GHz}$. 


\section{Antibacterial activity}

The synthesized Schiff bases and their oxovanadium (IV) complexes were screened in vitro for their antibacterial activity against the Gramnegative, Escherichia coli and the Gram-positive, Staphylococcus aureus bacterial strains by the agar well diffusion methods $[18,19]$.

\section{Results and Discussion}

The synthesized oxovanadium(IV) complexes with Schiff bases derived from the condensation of 4-amino-3-phenyl-5-mercapto-1,2,4-triazole with benzil are colored, crystalline solids and soluble in a different solvent like DMSO, acetonitrile, dimethylformamide, etc. The specific conductance of the different sample solutions was measured at $27^{\circ} \mathrm{C}$ and the cell constant at 1.000 (acceptance $1 \pm 10 \%$ ). The molar conductance of $\mathrm{ML}_{1}$ and $\mathrm{ML}_{2}$ solutions were found to be $19.6 \times 10^{3} \mu \mathrm{S} / \mathrm{M}$ and $19.8 .0 \times 10^{3}$ $\mu \mathrm{S} / \mathrm{M}$ respectively. The synthesized Schiff bases and oxovanadium(IV) complexes were stable in air and moisture at room temperature. The study of elemental analyses data for all synthesized ligands and complexes are in agreement with the compositions of the desired products. The molecular formula of synthesized compound was expected from analytical data as: $\mathrm{L}_{1}$ $=\mathrm{C}_{30} \mathrm{H}_{20} \mathrm{Cl}_{2} \mathrm{~N}_{8} \mathrm{~S}_{2}$ (mol. Wt. $=627$ ), $\mathrm{L}_{2}=\mathrm{C}_{30} \mathrm{H}_{22} \mathrm{~N}_{8} \mathrm{O}_{2} \mathrm{~S}_{2}$ (mol. wt. = 590), $\mathrm{ML}_{1}=\mathrm{C}_{30} \mathrm{H}_{18} \mathrm{Cl}_{2} \mathrm{~N}_{8} \mathrm{OS}_{2} \mathrm{~V}$ (mol. wt. $=$ 692), $\mathrm{ML}_{2}=\mathrm{C}_{30} \mathrm{H}_{20} \mathrm{~N}_{8} \mathrm{O}_{3} \mathrm{~S}_{2} \mathrm{~V}$ (mol. wt. = 655). They are further supported by other spectral analyses also.

\section{Magnetic moment and UV-Vis spectral analysis}

The magnetic moment of the oxovanadium(IV) complex, $\mathrm{ML}_{1}$ was measured and found nearly equal to $1.75 \mathrm{~B}$. M. at room temperature due to the presence of one unpaired electron which is similar to the characteristic value of oxovanadium(IV) complexes i.e. $d^{1}$ species [20]. The UV-Vis. spectra of oxovanadium(IV) complexes are characterized by three $\mathrm{d}-\mathrm{d}$ transitions that have been assigned using the energy level scheme proposed by Ballhausen and Gray for $\mathrm{C}_{4 \mathrm{v}}$ symmetry [14,21]. In the UV-Vis. spectrum of both oxovanadium(IV) complexes, the spectral band near $340-350 \mathrm{~nm}$ is due to $\mathrm{N} \rightarrow \mathrm{VO}$ charge transfer and the weak $d$ - $d$ transition is expected for square pyramidal geometry of the oxovanadium(IV) complexes i.e., the ligand to metal charge transfer (LMCT) from filled $p$-orbital of nitrogen to the vacant $d$-orbital of vanadium and $d$ - $d$ transition showed shoulder peak in complexes near 410-420 nm range [22]. And two other peaks near 200-210 nm and 250$260 \mathrm{~nm}$ are due to the $\pi \rightarrow \pi^{*}$ transition of azomethine and intra-ligand $n \rightarrow \pi^{*}$ transition of complexes respectively which are in good agreements with the UV-Vis. spectra of oxovanadium(IV) complexes that have been synthesized and studied before [7].

\section{FTIR analysis}

In the FTIR spectra, the strong absorption band at $1645-1592 \mathrm{~cm}^{-1}$ is due to $\mathrm{C}=\mathrm{N}$ bond stretching in Schiff bases giving the clue for condensation of one amino group of triazole during Schiff base formation but in the case of metal-Schiff base complexes, the lower value of $\mathrm{C}=\mathrm{N}$ bond stretching is due to the drift of lone pair density of azomethine nitrogen towards metal ion $[23,24]$. The band appeared at $980-970 \mathrm{~cm}^{-1}$ in the spectra of oxovanadium(IV) complexes is the characteristic feature of these complexes which is due to the $\mathrm{V}=\mathrm{O}$ stretching [25]. The band appeared near $2600 \mathrm{~cm}^{-1}$ is due to S-H stretching in Schiff bases but

Table 1: Physical properties and elemental analysis data of synthesized samples.

\begin{tabular}{|c|c|c|c|c|c|c|c|c|c|}
\hline Sample & \multirow{2}{*}{ Colors } & \multirow{2}{*}{$\begin{array}{c}\text { M.pt. } \\
\text { ( } \mathbf{C})\end{array}$} & \multicolumn{7}{|c|}{ Elemental Analysis [0 calculated] } \\
\cline { 4 - 9 } & & & $\mathbf{\%} \mathbf{C}$ & $\mathbf{\% H}$ & $\mathbf{\% N}$ & $\mathbf{\% O}$ & $\mathbf{\% V}$ & $\mathbf{\% S}$ & $\mathbf{\%} \mathbf{C l}$ \\
\hline $\mathrm{L}_{1}$ & Brown & 169 & 57.40 & 3.22 & 17.85 & - & - & 10.20 & 11.33 \\
& & & $(57.42)$ & $(3.21)$ & $(17.86)$ & & & $(10.22)$ & $(11.3)$ \\
\hline $\mathrm{L}_{2}$ & Brown & 156 & 61.60 & 3.70 & 18.88 & 5.40 & - & 10.42 & - \\
& & & $(61.00)$ & $(3.75)$ & $(18.97)$ & $(5.42)$ & & $(10.86)$ & \\
\hline $\mathrm{ML}_{1}$ & Greenish & 140 & 51.60 & 2.69 & 16.27 & 2.16 & 7.38 & 9.55 & 10.35 \\
& Brown & & $(52.03)$ & $(2.62)$ & $(16.18)$ & $(2.31)$ & $(7.36)$ & $(9.26)$ & $(10.24)$ \\
\hline $\mathrm{ML}_{2}$ & Dark green & 138 & 54.87 & 3.24 & 16.98 & 7.38 & 7.69 & 9.84 & - \\
& & & $(54.96)$ & $(3.08)$ & $(17.09)$ & $(7.32)$ & $(7.77)$ & $(9.78)$ & \\
\hline
\end{tabular}




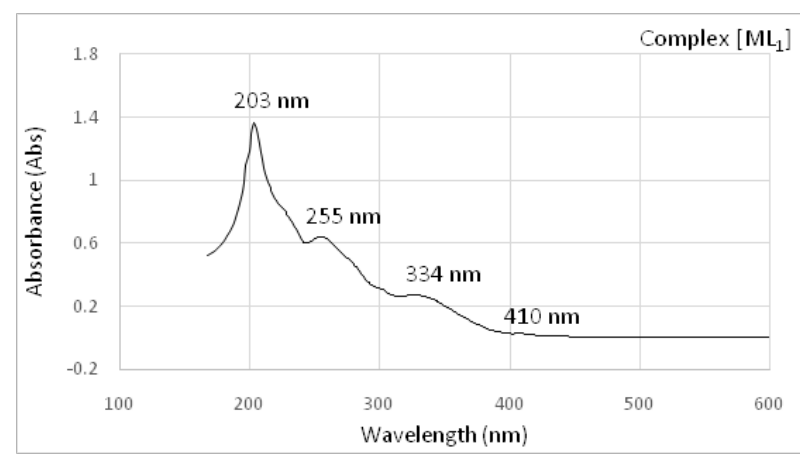

Figure 3: UV-Vis. spectra of oxovanadium(IV) complex, $M L_{1}$.
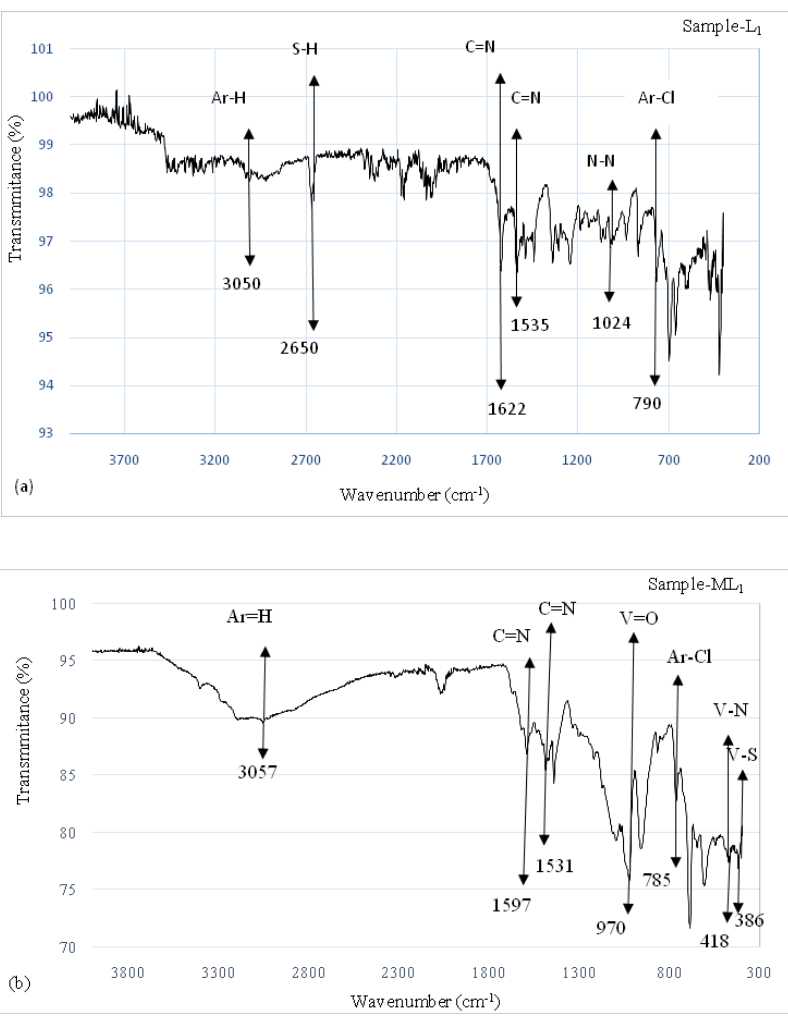

Figure 4: FTIR spectra of (a) ligand, $L_{1}$ and (b) complex, $M L_{1}$

not appeared in complexes provides the evidence for the formation of a bond between metal and S-atom of thiol group [5].
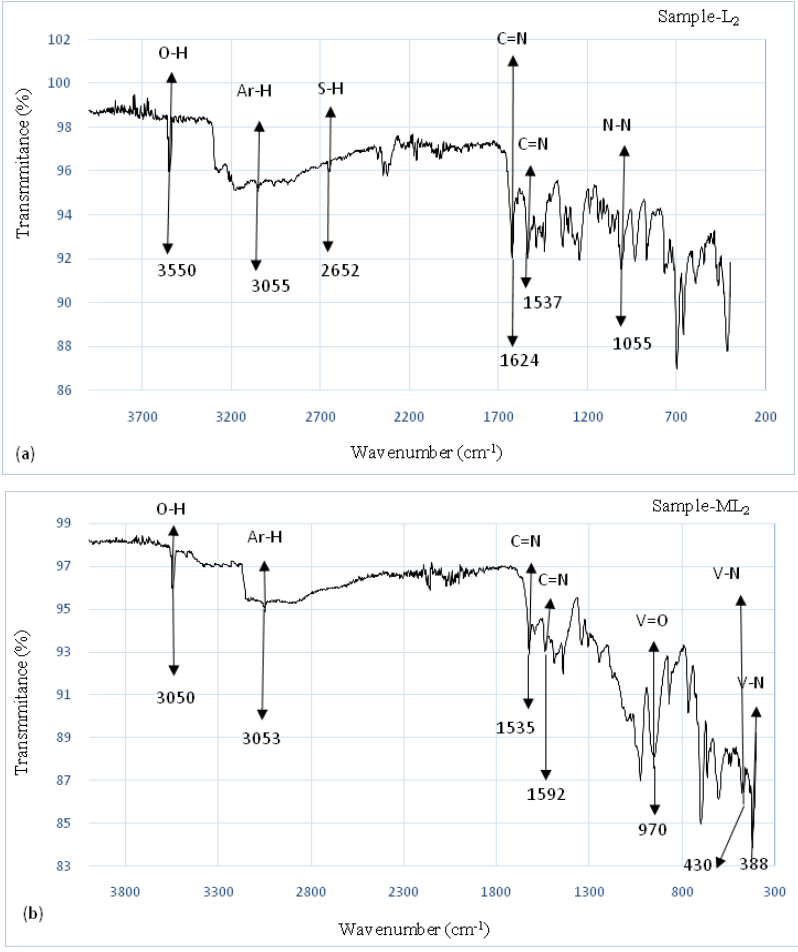

Figure 5: FTIR spectra of (a) ligand, $L_{2}$ and (b) complex, $M L_{2}$

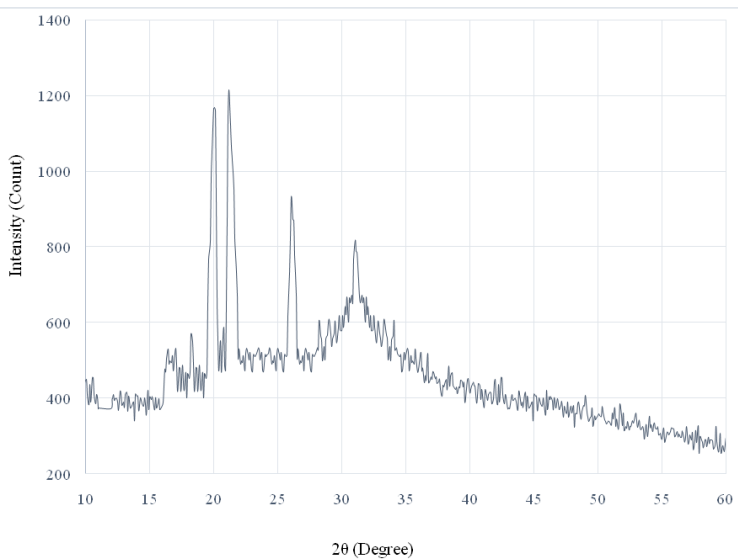

Figure 6: XRD spectra of an oxovanadium(IV) Complex

In this study, both the ligand $\mathrm{L}_{1}$ and $\mathrm{L}_{2}$ are coordinated tetradentately through two thiol-S atoms and two azomethine- $\mathrm{N}$ atoms. The ligands and complexes with the most diagnostic and significant IR peaks

Table 2: Diagnostic IR frequencies $\left(\mathrm{cm}^{-1}\right)$ of ligands $\left(L_{1}\right.$ and $\left.L_{2}\right)$ and their metal complexes $\left(M L_{1}\right.$ and $\left.M L_{2}\right)$

\begin{tabular}{|c|c|c|c|c|c|c|c|c|}
\hline Samples & $\begin{array}{c}\mathbf{v}(\mathbf{C}=\mathbf{N}) \\
\text { triazole } \\
\text { ring }\end{array}$ & $\begin{array}{c}\mathbf{v}(\mathbf{C}=\mathbf{N}) \\
\text { Azomethine }\end{array}$ & $\mathbf{v}(\mathbf{V}=\mathbf{O})$ & $\mathbf{v}(\mathbf{V}-\mathbf{S})$ & $\mathbf{v}(\mathbf{V}-\mathbf{N})$ & $\mathbf{v}(\mathbf{A r}-\mathbf{H})$ & $\begin{array}{c}\mathbf{v}(\mathbf{A r}- \\
\mathbf{C l})\end{array}$ & $\begin{array}{c}\mathbf{v}(\mathbf{A r}- \\
\mathbf{O}-\mathbf{H})\end{array}$ \\
\hline $\mathrm{L}_{1}$ & 1535 & 1622 & - & - & & 3050 & 790 & - \\
\hline $\mathrm{L}_{2}$ & 1537 & 1624 & - & - & & 3055 & - & 3550 \\
\hline $\mathrm{ML}_{1}$ & 1531 & 1597 & 970 & 386 & 418 & 3057 & 785 & - \\
\hline $\mathrm{ML}_{2}$ & 1535 & 1592 & 978 & 388 & 430 & 3053 & - & 3550 \\
\hline
\end{tabular}


for different groups and bonds are presented in the following Table 2 and their spectra are presented in Figures 4 and 5.

\section{X-ray diffraction spectra}

The most intense peaks appear at the $2 \theta$ value of 20.10 and 21.60 have full width at half maximum at 0.502 and 0.514 .respectively. The exact width of the peaks was calculated by fitting the data points with Lorentzian profile (with background fitted with a Gaussian profile). The average grain size (D) was calculated on the basis of Scherrer's equation

$$
D=\frac{K \lambda}{\beta \cos \theta}
$$

where $\mathrm{D}$ is the mean size of crystallites $(\mathrm{nm}), \lambda$ is the $\mathrm{X}$-ray wavelength, $\beta$ is the full width at half maximum (FWHM) in radians of the X-ray diffraction peak and $\theta$ is the Bragg's angle (deg.). The average crystalline size is around $17.174 \mathrm{~nm}$. This tells that average size is in nano scale range. In the calculation value of constant $\mathrm{K}$ was chosen to be 0.94 is constant [27].

\section{EPR spectra}

EPR spectroscopy is a useful technique and gives an idea about stereochemistry, type of ligand and degree of covalency of oxovanadium(IV) complexes. The EPR spectra of the complex $\mathrm{ML}_{1}$ was measured with microwave frequency $9.1 \mathrm{GHz}$ at liquid nitrogen temperature and the microwave frequency was calibrated against a powder DPPH sample ( $\mathrm{g}=2.0036)$. The EPR spectra of the synthesized sample, $\mathrm{ML}_{1}$ is given in Figure 7. The spectra show a single line at $\mathrm{g}=1.97$. In the EPR spectra of $\mathrm{ML}_{1}$ complex, the g-value was found typical of the spectra displaced by square-pyramidal oxovanadium(IV) complexes with an unpaired electron in an orbital of mostly $d_{x y}$ character [27]. The hyperfine splitting is not clearly seen in the spectra may be due to the fact that there is not so strong interaction of electron spins and nuclear spin of the vanadium metal [2]. The $g$ value

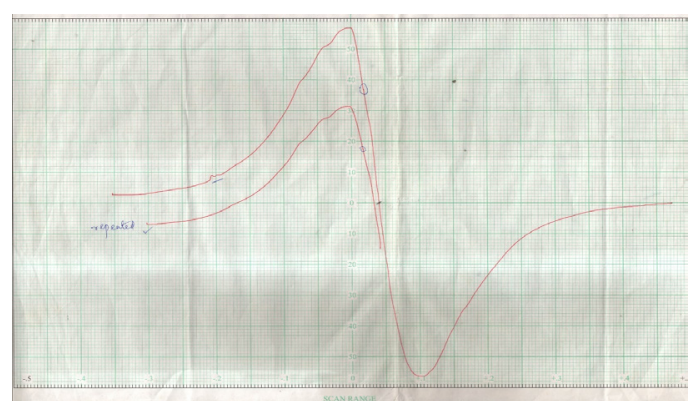

Figure 7 : EPR spectra of oxovanadium(IV) complex, $M L_{1}$ determined from the spectra is 1.98. The g-value can be determined from EPR spectra as:

$$
\mathrm{g}=\mathrm{h} v / \beta \mathrm{B}
$$

where $\mathrm{h}$ is constant known as the plank's constant, $\beta$ is also constant known as the Bohr magneton, $v$ is the frequency of microwave used in $\mathrm{Hz}$ and $\mathrm{B}$ is the magnetic field strength in Tesla.

\section{Antibacterial study (in vitro)}

The synthesized Schiff bases $\left(\mathrm{L}_{1}\right.$ and $\left.\mathrm{L}_{2}\right)$ and their oxovanadium(IV) complexes $\left(\mathrm{ML}_{1}\right.$ and $\left.\mathrm{ML}_{2}\right)$ were screened for in vitro antibacterial activity against one Gram-negative, E. coli and one Gram-positive, $S$. aureus bacterial strains by the agar well diffusion method (concentration $4 \mathrm{mg} / \mathrm{mL}$ ) [28].

The results obtained were compared with that of the standard drug neomycin as a positive control (PC) and solvent, DMSO as a negative control (NC) and are reported in Table 3.

Many in vitro antibacterial studies show that Schiff base ligands and oxovanadium(IV) complexes possess varying degrees of inhibitory effects $[29,30]$. The

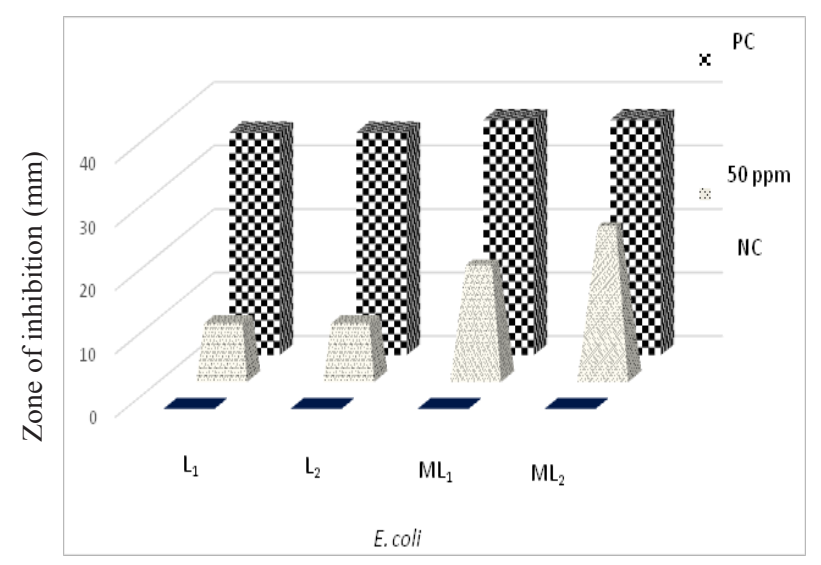

Figure 8 : Antibacterial activity of the ligands and their oxovanadium(IV) complexes against E. coli

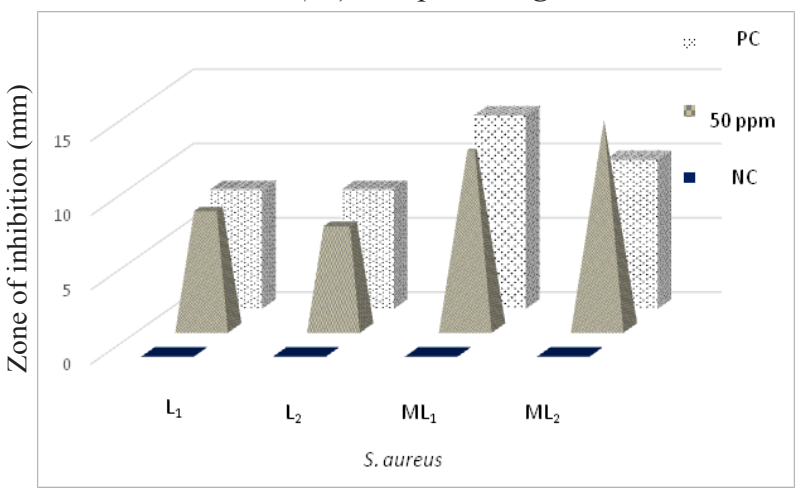

Figure 9 : Antibacterial activity of the ligands and their oxovanadium(IV) complexes against $S$. aureus 
Table 3. Antibacterial activity of synthesized ligands and their oxovanadium(IV) complexes with the zone of inhibition.

\begin{tabular}{|c|l|l|l|l|l|l|}
\hline Samples & \multicolumn{3}{|c|}{ E. coli (ZOI, mm) } & \multicolumn{3}{|c|}{ S. aureus (ZOI, mm) } \\
\cline { 2 - 7 } & $\mathrm{PC}^{*}$ & $\mathrm{NC} *$ & $50 \mathrm{ppm}$ & $\mathrm{PC}^{*}$ & $\mathrm{NC}$ & $50 \mathrm{ppm}$ \\
\hline $\mathrm{L}_{1}$ & 35 & - & 9 & 13 & - & 8 \\
\hline $\mathrm{L}_{2}$ & 35 & - & 9 & 13 & - & 7 \\
\hline $\mathrm{ML}_{1}$ & 37 & - & 18 & 20 & - & 12 \\
\hline $\mathrm{ML}_{2}$ & 37 & - & 24 & 20 & - & 14 \\
\hline \multicolumn{6}{c|}{$* \mathrm{PC}=$ Positive Control = Neomycin } \\
** $\mathrm{NC}$ Negative control = DMSO only.
\end{tabular}

antibacterial results of oxovanadium(IV) complexes with ligands containing chloro- and nitro- substituents show a significant inhibitory effect, therefore we have designed the synthesis of Schiff bases with chlorosubstituent [19].
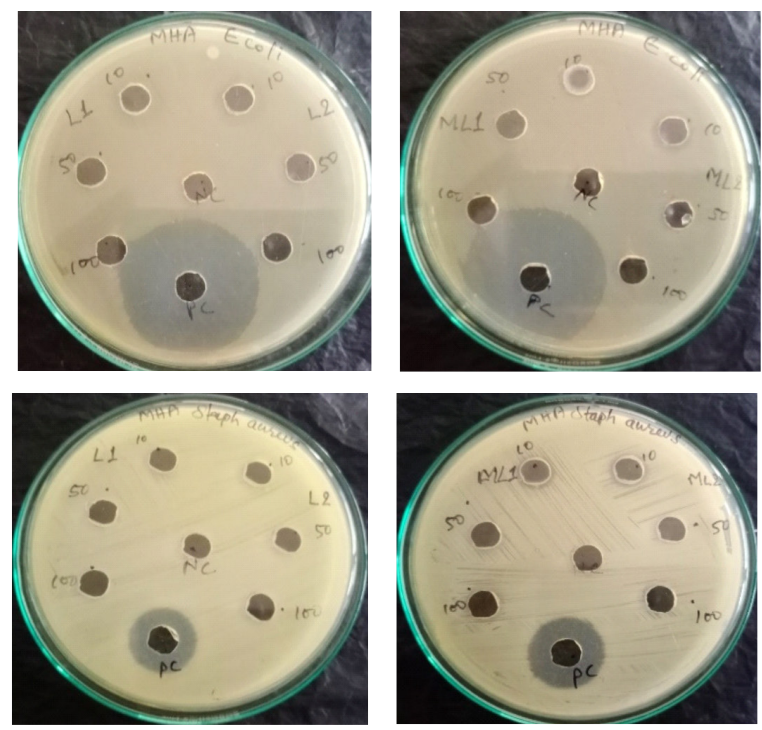

Figure 10: In vitro antibacterial screening of synthesized Schiff bases and oxovanadium complexes (Zone of Inhibition)

Here, the activity of the synthesized compounds was found to be more against $S$. aureus because the significant inhibition was displayed by all Schiff bases and oxovanadium(IV) complexes against all strains of Gram-positive bacteria. Generally, it was observed that the Gram-negative bacteria were resistant to all the synthesized compounds because the extra outer layer on the cell wall of the Gram-negative bacteria acts as a barrier and needs high penetration of the compounds to reach the cell $[5,15]$. The bacterial cell may also change the structure of its cell membrane and prevent the compound from entering the cell [23].

\section{Conclusions}

Two new Schiff base ligands have been synthesized by the condensation of the carbonyl compound, benzil and synthesizing two triazoles; 4-amino-3(2-chlorophenyl)-5-mercapto-1,2,4-triazole and 4-amino-3-(2-hydroxyphenyl)-5-mercapto1,2,4-triazole $\left(\mathrm{T}_{2}\right)$ from 2-chlorobenzoic acid and 2-hydroxybenzoic acid respectively as starting materials. The respective new oxovanadium(IV) complexes have been prepared from the reaction of these two Schiff bases with $\mathrm{VOSO}_{4} \cdot 3 \mathrm{H}_{2} \mathrm{O}$. The properties of the synthesized compounds were analyzed by elemental analysis, UV-Vis. spectroscopy, FTIR spectroscopy, EPR spectroscopy, XRD analysis and conductivity analysis. The characteristic bands appear in the IR and UV-Vis. spectra suggest the formation of macrocyclic Schiff base ligands and their coordination complex with vanadyl ion. Schiff bases act as dibasic, tetradentate chelating agents and coordination takes place through azomethine nitrogen and thiol sulfur via deprotonation. The XRD analysis provides information about the solid-state crystalline structure of the complexes and the most possible geometry and structure of the complexes have been established with the help of spectral studies. The square pyramidal geometry of synthesized complexes which is based on the different experimental data has been tentatively proposed.

The antibacterial properties of all the compounds were evaluated which suggested that the ligands and their metal complexes show good antibacterial activities against both Gram-positive and Gramnegative bacterial strain.

\section{Acknowledgments}

The authors acknowledge the facilities rendered by the Central Department of Chemistry, Tribhuvan University for necessary laboratory facilities, Nepal Academy of Science and Technology (NAST), Amrit Science College, Kathmandu, Central Drug Research Institute (CDRI), Lucknow, India and Indian Institute of Technology Bombay, Mumbai, India for various analysis and Med-Micro Research Laboratory, Kathmandu for biological studies.

\section{References}

1. Z. H. Chohan and S. H. Sumrra, Synthesis, characterization and biological properties of thienyl derived triazole Schiff bases and their oxovanadium(IV) complexes, Journal of Enzyme Inhibition and Medicinal Chemistry, 2012, 27(2), 187-193.(DOI:10.3109/14756366.2011.582686).

2. M. K. Sahani, S. K. Pandey, O. P. Pandey and S. K. Sengupta, A series of novel oxovanadium(IV) complexes: Synthesis, spectral characterization and antimicrobial study, Journal of Molecular 
Structure, 2014, 1074, 401-407. (DOI: 10.1016/j. molstruc.2014.06.015).

3. A. Bhattacharya, V. C. Purohit and F. Rinaldi, Environmentally friendly solvent-free processes: novel dual catalyst system in Henry reaction, Organic Process Research \& Development, 2003, 7(3), 254-258. (DOI: 10.1021/op020222c).

4. C. M. da Silva, D. L. da Silva, L. V. Modolo, R. B. Alves, M. A. de Resende, C. V. B. Martins and Â. de Fátima, Schiff bases: A short review of their antimicrobial activities, Journal of Advanced Research, 2011, 2(1), 1-8. (DOI: 10.1016/j. jare.2010.05.004).

5. Z. H. Chohan and S. H. Sumrra, Synthesis, characterization and biological studies of oxovanadium(IV) complexes with triazolederived Schiff bases, Applied Organometallic Chemistry, 2009, 24, 122-130. (DOI: 10.1002/ aoc.1590).

6. S. Y. Ebrahimipour, I. Sheikhshoaie, A. C. Kautz, M. Ameri, H. Pasban-Aliabadi, H. Amiri Rudbari, G. Bruno and C. Janiak, Mono- and dioxido-vanadium(V) complexes of a tridentate ONO Schiff base ligand: Synthesis, spectral characterization, X-ray crystal structure and anticancer activity, Polyhedron, 2015, 93, 99105. (DOI: 10.1016/j.poly.2015.03.037).

7. M. K. Sahani, U. Yadava, O. P. Pandey and S. K. Sengupta, Synthesis, spectral characterization and antimicrobial studies of nano-sized oxovanadium(IV) complexes with Schiff bases derived from 5-(phenyl/substituted phenyl)-2hydrazino-1,3,4-thiadiazole and indoline-2,3dione, Spectrochimica Acta. Part A, Molecular and Biomolecular Spectroscopy, 2014, 125, 189194. (DOI: 10.1016/j.saa.2014.01.041).

8. J. Pelletier, N. Domingues, M. M. C. A. Castro and C. G. Östenson, In vitro effects of bis(1,2-dimethyl3-hydroxy-4-pyridinonato)oxidovanadium(IV), or $\mathrm{VO}(\mathrm{dmpp}) 2$, on insulin secretion in pancreatic islets of type 2 diabetic Goto-Kakizaki rats, Journal of Inorganic Biochemistry, 2016, 154, 29-34. (DOI: 10.1016/j.jinorgbio.2015.11.004).

9. M. Selvaganapathy and N. Raman, Pharmacological activity of a few transition metal complexes: A short review, Journal of Chemical Biology \& Therapeutics, 2016, 1(2), 1-17. (DOI: 10.4172/2572-0406.1000108).

10. S. R. Welch, F. E. M. Scholte, M. Flint, P. Chatterjee, S. T. Nichol, É. Bergeron and C. F. Spiropoulou, Identification of 2'-deoxy-2'fluorocytidine as a potent inhibitor of CrimeanCongo hemorrhagic fever virus replication using a recombinant fluorescent reporter virus, Antiviral
Research, 2017, 147, 91-99. (DOI: 10.1016/j. antiviral.2017.10.008).

11. M. Amiri, D. Ajloo, M. Fazli, A. Mokhtarieh, G. Grivani and A. A. Saboury, Spectroscopic, electrochemical, docking and molecular dynamics studies on the interaction of three oxovanadium (IV) Schiff base complexes with bovine serum albumin and their cytotoxicity against cancer, Journal of Biomolecular Structure and Dynamics, 2018, 36(14), 3753-3772. (DOI: 10.1080/07391102.2017.1400467).

12. A. M. Sarhan, S. A. Elsayed, M. M. Mashaly and A. M. El-Hendawy, Oxovanadium(IV) and ruthenium(II) carbonyl complexes of ONS-donor ligands derived from dehydroacetic acid and dithiocarbazate: Synthesis, characterization, antioxidant activity, DNA binding and in vitro cytotoxicity: Biological applications of $\mathrm{V}(\mathrm{IV})$ and $\mathrm{Ru}(\mathrm{II})$ carbonyl complexes, Applied Organometallic Chemistry, 2019, 33(2), e4655. (DOI: 10.1002/aoc.4655).

13. A. Kajal, S. Bala, S. Kamboj, N. Sharma and V. Saini, Schiff Bases: A Versatile Pharmacophore, Journal of Catalysts, 2013, 2013, 1-14. (DOI: 10.1155/2013/893512).

14. P. Ghorbani, B. Ali, M. Homayouni-Tabrizi and P. Yaghmaei, Oxovanadium(IV) complexes of the pyridoxal Schiff bases: Synthesis, experimental and theoretical characterizations, QTAIM analysis and antioxidant activity, Journal of the Serbian Chemical Society, 2020, 85(1), 37-51. (DOI: 10.2298/JSC190129055G).

15. S. H. Sumrra and Z. H. Chohan, Antibacterial and antifungal oxovanadium(IV) complexes of triazole-derived Schiff bases, Medicinal Chemistry Research, 2013, 22(8), 3934-3942. (DOI: 10.1007/s00044-012-0388-0).

16. E. Bagdatli, E. Altuntas and U. Sayin, Synthesis and structural characterization of new oxovanadium(IV) complexes derived from azo-5pyrazolone with prospective medical importance, Journal of Molecular Structure, 2017, 1127, 653661. (DOI: 10.1016/j.molstruc.2016.08.026).

17. X.-Q. Luo, Q.-R. Liu, Y.-J. Han and L.-W. Xue, Vanadium complexes derived from fluorosubstituted Schiff bases: Synthesis, crystal structures and antimicrobial activity, Inorganic and Nano-Metal Chemistry, 2020, 50(9), 1-6. (DOI: 10.1080/24701556.2020.1726387).

18. B. P. Marasini, P. Baral, P. Aryal, K. R. Ghimire, S. Neupane, N. Dahal, A. Singh, L. Ghimire and K. Shrestha, Evaluation of antibacterial activity of some traditionally used medicinal plants against human pathogenic bacteria, BioMed 
Research International, 2015, 2015, 1-6. (DOI: $10.1155 / 2015 / 265425)$.

19. S. Torabi, M. Mohammadi and M. Shirvani, Antidiabetic, antioxidant, antibacterial and antifungal activities of vanadyl Schiff base complexes, Trends in Pharmaceutical Sciences TIPS, 2018, 4(2), 87-94.

20. S. Dekar, K. Ouari, S. Bendia, D. Hannachi and J. Weiss, Mononuclear oxovanadium(IV) Schiff base complex: Synthesis, spectroscopy, electrochemistry, DFT calculation and catalytic activity, Journal of Organometallic Chemistry, 2018, 866, 165-176. (DOI: 10.1016/j. jorganchem.2018.04.015).

21. C. J. Ballhausen and H. B. Gray, The Electronic Structure of the Vanadyl Ion, Inorganic Chemistry, 1962, 1(1), 111-122. (DOI: 10.1021/ ic50001a022).

22. B. Kołodziej, M. Morawiak, W. Schilf and B. Kamieński, Structure investigations of Schiff bases derived from 3-amino-1H-1,2,4-triazole, Journal of Molecular Structure, 2019, 1184, 207218. (DOI: 10.1016/j.molstruc.2019.02.027).

23. B. S. Far, G. Grivani, A. D. Khalaji, M. Khorshidi and A. Gholizadeh, A new six coordinated oxidovanadium(IV) Schiff base complex: Synthesis, characterization, crystal structure, thermal study and antibacterial activity, Journal of Molecular Structure, 2019, 1197, 361368. (DOI: 10.1016/j.molstruc.2019.07.055).

24. N. G. Kandile, M. I. Mohamed and H. M. Ismaeel, Synthesis of new Schiff bases bearing 1,2,4-triazole, thiazolidine and chloroazetidine moieties and their pharmacological evaluation, Journal of Enzyme Inhibition and Medicinal Chemistry, 2017, 32(1), 119-129. (DOI: 10.1080/14756366.2016.1238365).
25. A. Banerjee, M. Mohanty, S. Lima, R. Samanta, E. Garribba, T. Sasamori and R. Dinda, Synthesis, structure and characterization of new dithiocarbazate-based mixed ligand oxidovanadium( IV ) complexes: DNA/HSA interaction, cytotoxic activity and DFT studies, New Journal of Chemistry, 2020, 44(26), 1094610963. (DOI: 10.1039/D0NJ01246G).

26. M. L. Sharma, S. K. Sengupta and O. P. Pandey, Template synthesis, spectroscopic characterization and preliminary insulin-mimetic activity of oxovanadium(IV) complexes with N2O2 diazadioxa macrocycles, Spectrochimica Acta Part A: Molecular and Biomolecular Spectroscopy, 2012, 95, 562-568. (DOI: 10.1016/j.saa.2012.04.050).

27. C. Balakrishnan and M. A. Neelakantan, Crystal structure and bio-catalytic potential of oxovanadium(IV) Schiff base complexes derived from 2-hydroxy-4-(prop-2-yn-1-yloxy) benzaldehyde and alicyclic/aromatic diamines, Inorganica Chimica Acta, 2018, 469, 503-514. (DOI: 10.1016/j.ica.2017.09.060).

28. S. Uddin, Antimicrobial Activity of $\mathrm{Mn}$ Complexes Incorporating Schiff Bases: A Short Review, American Journal of Heterocyclic Chemistry, 2019, 5(2), 27. (DOI: 10.11648/j. ajhc.20190502.12).

29. A. Hameed, M. al-Rashida, M. Uroos, S. Abid Ali and K. M. Khan, Schiff bases in medicinal chemistry: a patent review (2010-2015), Expert Opinion on Therapeutic Patents, 2017, 27(1), 63-79. (DOI: 10.1080/13543776.2017.1252752).

30. L. K. Mandal, S. K. Panday and M. L. Sharma, Antimicrobial studies of Schiff's base ligands and their oxovanadium(IV) complexex, Journal of Nepal Chemical Society, 2018, 38,18-28 